\title{
THE MANAGEMENT OF TURF TOE - A SYSTEMATIC REVIEW
}

\author{
Louis Hainsworth, John McKinley \\ University of Edinburgh, Edinburgh, United Kingdom
}

\begin{abstract}
Background. Turf toe is used to describe an injury occurring at the plantar aspect of the metatarsophalangealsesamoid complex of the hallux. Typically seen in athletes, it occurs due to hyperdorsiflexion and axial loading of the hallux metatarsophalangeal joint with the foot fixed in equinus. The injury causes pain and joint instability, missed athletic activity and potentially end careers. Turf toe can be managed conservatively or operatively, with controversy regarding the indications for operative intervention. This study aims to conduct a systematic review to determine whether and in what circumstances operative intervention is superior to conservative management of turf toe in adults.

Methods. A systematic review of the literature was performed using PubMed, Embase, Cochrane and Scopus databases. The search terms used were "turf toe", "first metatarsophalangeal joint injury", "conservative", "nonoperative", and "operative". All articles published in English reporting on the management of turf toe were reviewed. The primary outcome measure was the time to return to pre-injury activity with the secondary outcome of the time to symptom resolution.

Results. Seven studies met the inclusion criteria. Three patients were successfully managed conservatively returning to athletic activity, on average at 12 weeks. Seventeen patients underwent surgical intervention with an average return to athletic activity at 18 weeks.

Conclusion. Operative intervention was shown to give a successful outcome in patients with grade three turf toe injuries or those who have failed conservative management. However, there is insufficient evidence to determine whether operative intervention is superior to conservative management.
\end{abstract}

Keywords: turf toe, first metatarsophalangeal joint injury, conservative, nonoperative, and operative.

\section{INTRODUCTION}

$\mathrm{T}$ urf toe is an umbrella term used to describe an injury occurring at the plantar aspect of the metatarsophalangeal-sesamoid complex of the hallux. Bowers and Martin (1976) first coined the term in 1976 in response to injuries of the hallux seen in American Football players playing on artificial turf. Since then, increasing attention has been given to the hallux metatarsophalangeal joint injuries. Clanton and Ford (1994) identified the foot as the third most common time loss injury amongst university athletes, of which the hallux metatarsophalangeal joint was a significant proportion. The incidence of turf toe is difficult to assess with the injury often unreported. When
Bowers and Martin (1976) first described the injury they noted turf toe occurring 5.4 times per season in a group of 500 collegiate American Football players and similar results were found by Coker, Arnold, and Weber (1978) in a second group of collegiate American football players. Within professional American football players, Rodeo et al. (1990) reported an incidence of $45 \%$ in 1990 with $83 \%$ of injuries occurring on artificial turf. The current belief is that this has decreased with a recent retrospective 5-year analysis of collegiate American football players (George, Harris, Dragoo, $\&$ Hunt, 2014) reporting an incidence of 0.062 per 1000 athlete exposures. 
Anatomy and biomechanics of the hallux metatarsophalangeal joint. The hallux metatarsophalangeal joint is a condyloid joint which permits movement as a hinge joint and also allows sliding movements. On toe off, during normal gait, dorsiflexion occurs at the hallux metatarsophalangeal joint. This initial 20 degrees of dorsiflexion occurs as the head of the metatarsal pivots around the proximal phalanx. To dorsiflex beyond this the hallux metatarsal is required to slide backwards from the articular surface of the phalanx which allows the final 60 degrees of normal active dorsiflexion (Joseph, 1954).

The hallux metatarsophalangeal joint has minimal bony stability secondary to the proximal phalanx's shallow articular cavity in which the head of the metatarsal lies. The majority of the joints stability therefore comes from the capsule, ligaments and surrounding tendons. Fan shaped medial and lateral collateral ligaments travel between the first metatarsal and proximal phalanx and provide valgus and varus stability. These are essential structures for athletes when they are rapidly changing directions while sprinting. This is seen in American football when undertaking a "cut move" most commonly performed by running backs and wide receivers (McCormick \& Anderson, 2009). The plantar plate is a fibrous thickening of the plantar capsule which courses from a relatively weak attachment of the metatarsal head to a strong attachment to the proximal phalanx. Along with these structures the joint is dynamically stabilised by the flexor hallucis brevis and its associated sesamoids, adductor hallucis and abductor hallucis tendons (Lohrer, 2001).

During normal gait the capsular ligamentous complex of the hallux metatarsophalangeal joint withstands $60 \%$ of body weight (Stokes, Hutton, Stott, \& Lowe, 1979). This increases up to $300 \%$ of body weight in normal athletic activity, and $800 \%$ of body weight when undertaking a running jump (Nigg et al., 1986). It is therefore clear that a strong metatarsophalangeal-sesamoid complex of the hallux is essential when undertaking athletic activity, and any injury of this joint will significantly impact performance ability.

Mechanism of turf toe injury. The mechanism of injury is a summation of the amount of energy imparted to the structure (in this case the great toe) and the extent and direction of abnormal range of force at the time of the force (VanPelt, Saxena, \& Allen, 2012). The most common mechanism of injury is a combination of hyperdorsiflexion and axial loading of the hallux metatarsophalangeal joint with the foot fixed in equinus (McCormick \& Anderson, 2010). As a result of this, a compressive force is applied to the base of the proximal phalanx and dorsal aspect of the articular surface of the hallux metatarsal, which can lead to intra-articular injury. A distraction force occurs at the capsule ligamentous plantar complex which can result in a range of pathologies including sprain or strain, partial or complete plantar plate tear and sesamoid fracture. A complete disruption of the plantar structures can even lead to dorsal dislocation of the joint (Van Pelt et al., 2012).

Variations of the classical mechanism can occur, but this is dependent upon the point of the force and position of the hallux (McCromick \& Anderson, 2009). Watson, Anderson, and Davis (2000) described a valgus force which resulted in a more significant injury to the medial plantar capsular ligamentous sesamoid complex. This mechanism was also described by Douglas, Davidson, Robinson, and Bedi (1997) in which a footballer experienced this injury due to a slide tackle from the side. In cases of injury to the medial complex, there is a resultant contracture of the lateral complex leading to a traumatic hallux valgus and bunion deformity McCormick and Anderson 2009. A varus force resulting in injury has been reported in rare instances, which leads to injury of the lateral complex structures and a hallux varus deformity (Mullis \& Miller 1980).

Risk factors. A flexible shoe in combination with a hard artificial surface was believed to be the source of turf toe injury when first postulated By Bowers in 1976. Bowers (1976) noted that traditional American football boot contained a metal plate making it rigid, in comparison to more modern football boots which were flexible. This increased flexibility provided little support to the hallux metatarsophalangeal joint, thus providing a greater risk of injury (Prieskorn, Graves, \& Smith 1993). Artificial surfaces (turf), from which the condition gets its name, have been shown to increase risk, despite the development of third generation artificial turf. Artificial turf consists of a layer of synthetic fibres with or without a layer of infill. Traditionally sand was used infill but other options include silicone or rubber. No research has currently investigated the rate of turf toe on the current $4^{\text {th }}$ generation artificial surfaces, which is characteristically softer and more shock absorbent 
than the third. However, it should be noted that the condition is not exclusive to artificial surfaces and has been reported to occur on natural grass too (Mullis \& Miller 1980). George et al undertook a retrospective review of 5 seasons of collegiate American football and noted the turf toe injury was more likely to occur during games when compared to practice. Along with this, the position of the player affected their risk with running backs and quarterbacks more likely to suffer turf toe injury (George et al., 2014).

Presentation and clinical assessment. The presentation of turf toe requires a high index of suspicion in all patients presenting with pain or swelling of the hallux metatarsophalangeal joint. On observing the hallux, it should be observed for swelling, bruising or malalignment. Bruising on the plantar surface should raise suspicion of disruption of the plantar capsular ligamentous sesamoid complex, with the possibility of a sesamoid fracture (VanPelt et al., 2012) The joint and surrounding structures should be palpated, with tenderness over the dorsal aspect of the base of the proximal phalanx raising the suspicion of intra-articular injury (McCormick \& Anderson, 2010).

The stability of the joint should be assessed by providing a dorsal and plantar stress for the plantar and dorsal complexes along with a varus and valgus stress for the collateral ligaments (McCormick \& Anderson, 2010). Comparing the assessment with the non-injured side can be helpful in evaluating any change in stability. Active and passive range of motion and power should be assessed to ensure the integrity of flexor and extensor tendons. A reduced strength in active flexion suggests a disruption of the plantar plate. Neurovascular compromise is rare and is only seen in non-reduced dislocations of the hallux metatarsophalangeal joint (VanPelt et al., 2012).

Imaging. If there is a clinical suspicion of turf toe injury, weightbearing anteroposterior lateral and sesamoid axial view radiographs should be undertaken. These are often normal; however, a small avulsion fracture of the proximal phalanx or sesamoid fracture may be seen suggestive of plantar plate disruption (McCormick \& Anderson, 2010). Comparison radiographs of the other foot are useful to compare position of the sesamoids. Prieskorn et al. (1993) have demonstrated that patients who have a complete plantar plate rupture have proximal migration of the sesamoids.

Fluoroscopic imaging can be used to provide a dynamic assessment of the metatarsophalangeal joint and sesamoid complex. Lack of distal sesamoid movement with hallux dorsiflexion is suggestive of plantar plate rupture (Lohrer, 2001). Magnetic resonance imaging (MRI) should be used in all grade 2 and grade 3 turf toe injuries to identify osseous, articular or soft tissue injury, aiding in grading and treatment of turf toe injury.'

Classification. Multiple researchers have attempted to classify turf toe injuries. Clanton and Ford (1994) originally described a system based on clinical assessment and Anderson modified this with the addition of radiograph and MRI findings (Table1).

Table 1. Anderson turf toe classification system

\begin{tabular}{|c|c|c|c|c|}
\hline Grade & Pathology & Clinical & Radiographs & MRI \\
\hline 1 & $\begin{array}{l}\text { Strain of } \\
\text { the capsule } \\
\text { without loss of } \\
\text { continuity }\end{array}$ & $\begin{array}{l}\text { Normal range of motion, no vis- } \\
\text { ible ecchymosis, and the patient } \\
\text { can bear weight. }\end{array}$ & Normal & $\begin{array}{l}\text { Intact soft tissue complex } \\
\text { with surrounding oedema }\end{array}$ \\
\hline 2 & $\begin{array}{l}\text { Partial tear } \\
\text { of the plantar } \\
\text { plate and } \\
\text { capsule }\end{array}$ & $\begin{array}{l}\text { Painful motion and difficulty } \\
\text { weight bearing }\end{array}$ & Normal & $\begin{array}{l}\text { Soft tissue oedema and } \\
\text { high signal intensity that } \\
\text { does not extend through } \\
\text { the full thickness of the } \\
\text { plantar plate }\end{array}$ \\
\hline 3 & $\begin{array}{l}\text { Complete tear } \\
\text { with loss of } \\
\text { continuity of } \\
\text { plantar plate } \\
\text { and capsule }\end{array}$ & $\begin{array}{l}\text { Associated injuries including } \\
\text { sesamoid fracture, diastasis } \\
\text { of bipartite sesamoids, dorsal } \\
\text { metatarsal articular impaction, } \\
\text { and proximal sesamoid migration }\end{array}$ & $\begin{array}{l}\text { May show avulsion fracture } \\
\text { of the proximal phalanx, } \\
\text { sesamoid fracture, proximally } \\
\text { migrated sesamoid, } \\
\text { metatarsophalangeal joint } \\
\text { dislocation }\end{array}$ & $\begin{array}{l}\text { High signal intensity } \\
\text { completely traversing } \\
\text { the plantar capsulo- } \\
\text { ligameontous complex and } \\
\text { sesamoid and chondral } \\
\text { injury }\end{array}$ \\
\hline
\end{tabular}


Current Standings. Turf toe injury causes major issues in foot function with significant clinical features, which leads to substantial time away from athletic activities for athletes. Clanton, Butler, and Eggert (1986) found that, despite treatment, 50\% of those suffering turf toe injury have persistent symptoms at 5 years. The impact of the loss of a professional athlete from his team is significant. It has been shown that injuries such as turf toe have a significant influence on the performance of a team. An eleven-year prospective study showed that injuries had a significant influence on professional football teams in both domestic and continental football tournaments (Hägglund et al., 2013). For the athlete, time away from athletic activity has significant financial implications with loss of performance bonuses. With a severe turf toe injury, it is likely that a substantial amount of training will be missed, therefore inhibiting performance of the individual and the team, and there is even the potential for this injury to end their career (Bouchette, 1985; Florio, 2015).

Despite the potential severity of the injury, management of turf toe does not have any clear evidence based guidelines at present. Current management of grade 1 and 2 injuries is conservative with initial rest, ice, compression and elevation. Following this, a period of rest is required with support of the hallux metatarsophalangeal joint, whether this be taping or a walking boot (Prieskorn, Graves, \& Smith, 1993). There remains much controversy over the management of grade 3 turf toe injuries and the indications for operative intervention. The current indications identified for surgical intervention are:

- large capsular avulsion with unstable joint,

- diastasis or retraction of sesamoids,

- vertical instability,

- traumatic hallux valgus deformity,

- chondral injury,

- intra-articular loose body,

- sesamoid fracture,

- failed conservative treatment.

These are based on level 5 evidence and expert opinion, but as yet no systematic review has ever been undertaken.

\section{METHODS}

Search strategy and selection criteria. A systematic review of the literature was performed using the PubMed, Embase, Cochrane and Scopus databases. They were searched from inception to 30th November 2016, English language articles only. The search terms used were "turf toe", "first metatarsophalangeal joint injury", "conservative", "nonoperative", and "operative". Relevant articles were also identified by cross-referencing the citation lists of included articles. Due to the expectation that there were likely to be few randomised controlled trials, all study designs were included. Articles were included if they met the criteria of: published in English, contained original data, and reported on a nonoperative or operative management strategy for turf toe. Articles were excluded if they solely reported on: under 18's, management of isolated sesamoid fractures or no outcomes reported. The primary outcome measure was the time to return to pre-injury activity with the secondary outcome of the time to symptom resolution.

Data extraction and data items. The initial search produced a total of 409 articles. Duplicates were then removed and three further articles were identified through cross-referencing the citation list of relevant articles, giving a total of 260 articles. A single non blind author independently screened all articles from the search; initially titles and abstracts were screened for eligibility. Following this process 201 articles were excluded. After the initial screening, full articles were reviewed, where available, by the same non blind author and a reason provided if articles were excluded (Appendix 1). For included studies, the same author extracted data using a data extraction sheet which was developed based on the Cochrane consumers' data extraction template (Appendix 2). Data items extracted from the included articles were:

- study design,

- sample size,

- participant age,

- participant gender,

- grade of turf toe injury,

- time from injury to treatment initiation,

- type of treatment,

- time to return to pre-injury activity,

- time to resolution of symptom,

- length of follow up.

No changes were made to the search strategy, selection criteria, data extraction and data items following the initial design proposed.

Data analysis. Due to the fact only 7 studies were included, four case series and 3 case reports, with a small number of participants, a metaanalysis was not undertaken. Data was analysed 
using qualitative analyses and descriptive statistics. Time to return to pre-injury activity was measured in weeks and was converted from months and days where necessary. This was also the case for the secondary outcome of time to resolution of symptoms.

\section{RESULTS}

Study selection. A total of 7 studies met the inclusion criteria of this systematic review. The databases of PubMed, Embase, Cochrane and Scopus provided a total of 409 articles with a further 3 arising from the references of these articles. Of these studies 260 remained following removal of duplicates. These 260 articles were screened and 201 articles were removed as they clearly did not address the systematic review hypothesis. 59 articles had their full text articles reviewed in detail, where available. 52 of these articles failed to meet the inclusion criteria as described and were therefore excluded. The reason for each individual studies exclusion can be seen in Appendix 2. Seven studies met the inclusion criteria and were therefore included in this review. There were no unpublished relevant studies obtained for this systematic review.
Figure 2 shows the PRIMSA flow diagram for this review.

Study Characteristics. Methods. There were no randomized control trials on the management of turf toe. All 7 studies are retrospective case studies (4) or case reports (3) published in English (Table 2). Each study was at a single centre. The studies identified patients with turf toe through clinical or radiological (MRI) diagnosis and describe the management of their patient population and outcomes. The duration of follow up was highly variable between studies ranging from 6 months to 10 years.

Participants. The studies included in this review had a total of 48 participants. The participants were all adults (age over 18) with a turf toe injury. Across the studies there was no limitation of whether this was an acute or chronic presentation of turf toe injury.

Intervention. The interventions the patients received consisted of conservative or operative intervention. Conservative intervention varied across the studies but all included an initial period of rest. This was then followed by supporting the injury with a range of techniques, including but not limited to: taping, toe spika, walking boot and a

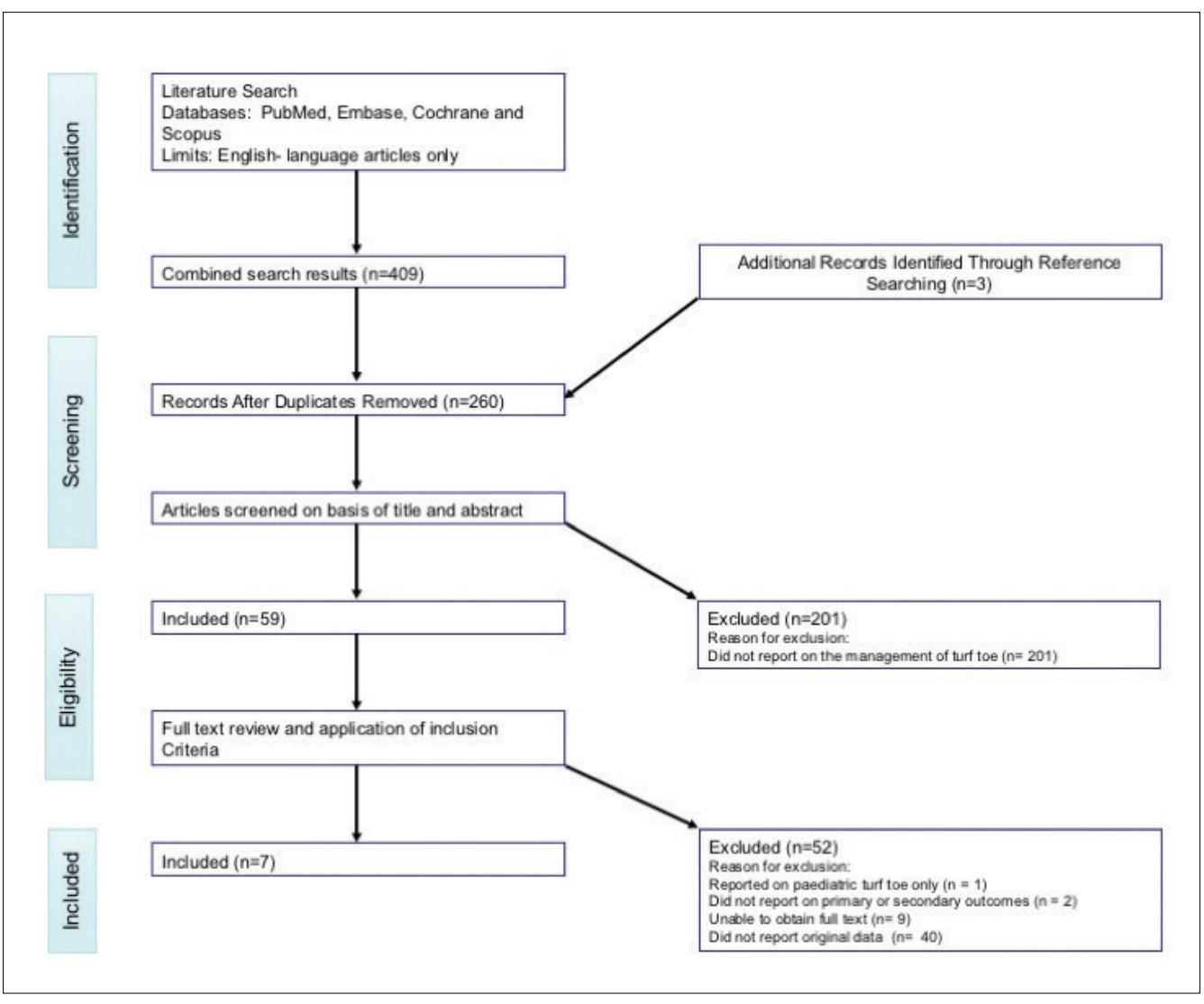


Table 2. Summary table of included studies evaluating the management of turf toe Injury

\begin{tabular}{|c|c|c|c|c|c|c|}
\hline Author & $\begin{array}{l}\text { Study } \\
\text { design }\end{array}$ & $\begin{array}{l}\text { Number of } \\
\text { participants }\end{array}$ & $\begin{array}{l}\text { Participant } \\
\text { age range }\end{array}$ & $\begin{array}{l}\text { Initial type of } \\
\text { management }\end{array}$ & Outcomes reported & $\begin{array}{l}\text { Length of } \\
\text { follow up }\end{array}$ \\
\hline Anderson et al. & $\begin{array}{l}\text { Case } \\
\text { Series }\end{array}$ & 19 & $18-33$ & $\begin{array}{l}10 \text { Conservative } \\
9 \text { Operative }\end{array}$ & $\begin{array}{l}\text { Primary and Secondary outcomes } \\
\text { reported in those who underwent } \\
\text { operative intervention }\end{array}$ & $1-10$ years \\
\hline Coker et al. & $\begin{array}{l}\text { Case } \\
\text { Series }\end{array}$ & $\begin{array}{c}18 \text { (only } \\
8 \text { reported on) }\end{array}$ & N/A & $\begin{array}{l}5 \text { conservative } \\
3 \text { operative }\end{array}$ & $\begin{array}{l}\text { Primary and secondary } \\
\text { outcomes }\end{array}$ & $\mathrm{N} / \mathrm{A}$ \\
\hline Drakos et al. & $\begin{array}{l}\text { Case } \\
\text { Series }\end{array}$ & 3 & $19-21$ & $\begin{array}{l}1 \text { Conservative } \\
2 \text { Operative }\end{array}$ & Primary outcome & 6 Months \\
\hline Faltus et al. & $\begin{array}{l}\text { Case } \\
\text { Series }\end{array}$ & 5 & $18-22$ & $\begin{array}{l}2 \text { Conservative } \\
3 \text { Operative }\end{array}$ & $\begin{array}{l}\text { Primary and secondary } \\
\text { outcomes }\end{array}$ & N/A \\
\hline Lohrer et al. & $\begin{array}{l}\text { Case } \\
\text { Report }\end{array}$ & 1 & 26 & Conservative & Primary outcome & 6 Months \\
\hline Roche et al. & $\begin{array}{l}\text { Case } \\
\text { Report }\end{array}$ & 1 & 31 & Operative & Primary outcome & $\begin{array}{l}2 \text { years } \\
6 \text { months }\end{array}$ \\
\hline Sahin et al. & $\begin{array}{l}\text { Case } \\
\text { Report }\end{array}$ & 1 & 19 & Conservative & $\begin{array}{l}\text { Primary and secondary } \\
\text { outcomes }\end{array}$ & 10 months \\
\hline
\end{tabular}

cast. For those undergoing operative intervention there was again a variety of procedures performed, as there is no single described procedure or approach recognised for managing turf toe.

Outcomes. Primary - in all studies the primary outcome of time to return to athletic activity was reported. Two studies failed to report this in all their participants. Anderson et al reported this outcome in the 9 participants who underwent operative intervention but not for those undergoing conservative management. Coker et al reported the primary outcome in 8 of the 18 participants but did not report this in the other 10 of his case series.

Secondary - the secondary outcome of time to resolution of symptoms was rarely reported on across the studies. Many studies coincided resolution of symptoms with increasing athletic activity, this therefore being recognised as the same. However, other studies with long term follow up patients noted that patients had resumed athletic activity despite on-going symptoms from the turf toe injury.

Risk of bias within studies. To assess the risk of bias within the included studies, a risk of bias assessment was conducted using the Cochrane collaboration of risk of bias tool. This was undertaken by a single non blind author. All seven studies were shown to have a high risk of bias in multiple areas. All studies were shown to have a high risk of selection, performance and detection bias. The reason for the high risk in bias across the studies is related to study design, consisting of case series and case reports. All studies suffered from a lack of randomisation, concealment and blinding.

Conservative management of turf toe. The systematic review revealed a total of 20 participants who underwent conservative management initially. Of this group, 4 were deemed to have failed conservative management and subsequently underwent surgical intervention. The duration of conservative management the patients received before it was deemed to have failed was not consistently reported across the studies. Only 3 studies reported on the time to return to preinjury activity in their conservatively managed participants. This consisted of three participants who had the primary outcome reported of the average time to return to pre-injury activity, which was 12 weeks (range 3-24 weeks). No studies reported on the average time to symptom resolution in those who underwent conservative management.

Operative management of turf toe. The grade of injury for those who underwent operative intervention included:

- Two grade 2 injuries which failed conservative management.

- Fifteen grade 3 injuries in which it was the primary treatment.

- One grade 3 injury which failed conservative management.

The time to return to pre-injury activity was clearly reported in 6 of the studies. In this group the average time to return to pre-injury activity 
was 18.16 weeks (ranging from 15-24 weeks, Appendix 3). The exact operative procedure of these participants was highly variable. There was variation reported in surgical approach: medial, lateral or both. There was also variation in the operative technique, which comprised of including direct suture repair of the plantar plate, sesamoidectomies, abductor hallucis transfer to restore the plantar plate, and the use of a Kirschner wire to hold the toe in plantar flexion to relax the soft tissue repair.

Few studies reported on the average time to resolution of symptoms, with some studies such as Roche and Calder (2014) and Sahin, Atici, Bilgen, and Bilgen (2004), stating that symptoms were resolved at the time of resolution of pre injury activity. Anderson et al reported that 2 of the 9 patients who underwent operative intervention had ongoing symptoms within a follow up period of 1-10 years. One patient had joint stability but reported suffering persistent pain upon toe-off. The second developed severe progressive degenerative joint disease. Along with this, Coker et al. (1978) reported two cases of ongoing symptoms despite intervention.

Only one case was reported where the patient was unable to resume pre-injury athletic activity. In this case, an American football player suffered a turf toe injury and sesamoid fracture. This was managed conservatively for 5 months prior to operative intervention. Unfortunately, the participant was unable to resume pre-injury athletic activity and after a 5 year follow up he was unable to perform the toe off phase which enabled him to run secondary to this injury.

\section{DISCUSSION}

Turf toe injury is a significant cause of missed athletic activity for both the amateur and professional athlete causing significant morbidity and can lead to the end of an athlete's career (Bouchette, 1985; Drakos et al., 2015). Since the condition was first described in 1976 there has been ongoing debate as to when operative intervention is superior to conservative management. This systematic review has evaluated the outcomes of patients who underwent either conservative or operative intervention, and also identified those who underwent operative as a result of failed conservative intervention.
Overall, the review highlighted that the current evidence is far from robust. This makes the identification of definitive surgical indications, and a direct comparison of the outcomes of patients, who undergo conservative or operative intervention for turf toe very difficult. Interestingly, no evidence was found for the management of grade 1 turf toe injuries, and there was limited evidence on the conservative management of grade 2 injuries. The current professional opinion is that these should be managed conservatively. The reasons for the lack of evidence could be that the injury is often missed or overlooked leading to difficulty in identifying cases. Secondly, given that grade 1 and grade 2 turf toe tends to be managed conservatively, the lack of evidence could suggest that there is little controversy over their management.

Conservative management. In the cases where grade 2 injuries were reported to have been managed conservatively, the time to return to pre injury had a large range, from 3-24 weeks. This wide range highlights that despite the presence of a classification system, there is significant variety in the severity of the injury within each grade. The time to return to pre injury activity will also depend on the patients demands, such as the activity undertaken and the level (amateur or professional) they are performing at.

There was significant variation in what conservative management of turf toe involved. Drakos et al. (2015) proposed an initial period of 5 weeks nonweightbearing in cast immobilisation before a period of partial weightbearing in a walking boot and then an athletic shoe with a carbon or steel insert to limit dorsiflexion. In comparison to this Faltus et al. (2014) proposed a shorter period (2.5 weeks) of nonweightbearing in a walking boot with the hallux metatarsophalangeal joint being taped. After this a period of partial weightbearing for a week and full weightbearing at 4 weeks with the use of a carbon orthotic. Participants were then able to progress to jogging, agility drills and non-contact sporting activities once symptoms had decreased at 6 weeks (Faltus et al., 2014). The focus of the rehabilitation programme was that of improving the strength and proprioception of the injured area and surrounding structures before progressing to full activity (Faltus et al., 2014). This significant variation in practice highlights that there is no current standard for conservative management and is likely to vary significantly in clinical practice. 
Operative management. A total of 18 participants underwent operative intervention for turf toe injury with the most common indication being a grade 3 injury (Appendix 3). No grade 1 injuries underwent operative intervention, and two grade 2 injury that had failed conservative management underwent operative intervention. Only one grade 3 injury was found to have been managed conservatively; this was unsuccessful and subsequently underwent surgery Across the studies there was significant variability in the operative procedure undertaken. The approaches described included medial, lateral or a dual approach. The technique of repair of the plantar plate also showed significant variability: which comprised of including direct suture repair of the plantar plate, sesamoidectomies, abductor hallucis transfer to restore the plantar plate, and the use of a Kirschner wire to hold the toe in plantar flexion to relax the soft tissue repair. There have been no studies that have compared the surgical approach or surgical technique of turf toe.

The current widely cited indications for surgery are based on expert opinion rather than evidence. This systematic review highlights that there is insufficient evidence to determine in which circumstances operative intervention is superior to conservative management. However, it does show that for grade 3 injuries, and for those turf toe injuries that failed conservative management, undergoing operative intervention has successful outcomes. Therefore, we recommend that operative intervention should be considered in all cases of grade 3 turf toe and in all cases where conservative management has failed. The strength of this recommendation is based on very low quality evidence as per its' GRADE score.

While failed conservative management is a proposed indication for surgery, it is not clearly defined as what a failure of conservative management is. Sahin et al. (2004) defined this as on-going pain and instability despite 6 months of conservative management. Whereas Lohrer (2001) defined this as persisting symptoms after 3 weeks of conservative management. The lack of a standardised conservative management regime makes it difficult to define when conservative management has failed, due to the significant variability. Therefore, a case by case assessment of patients' needs should be undertaken when offering operative intervention for patients who have ongoing clinical features.

The average time to return to pre-injury athletic activity in those undergoing operative intervention for turf toe injuries was found to be just over 18 weeks. This is an important finding to note as it allows us to guide both professional individual athletes and those performing in team sports of the expected recovery time, which may aid decision making on timing for surgery. While the majority of cases managed operatively had a successful outcome, it should also be noted that Coker et al. (1978) described a case in which a running back in American Football was unable to return to athletic activity following operative intervention. He subsequently was unable to run when reviewed 5 years post-operatively. This case highlights that operative intervention is not a guarantee of successful outcome and all patients should be counselled about this prior to surgery. Furthermore, the level of performance following operative repair of turf toe injury can be questioned. While the review shows that patients can return to athletic activity, there is no detail as to how they performed competitively following the injury, and how much of a phased return was necessary.

Limitations of the included studies. The risk of bias of studies included in this systematic review is generally high throughout. Given the study designs, case series and case reports there was no randomisation or concealment of the participant's treatment giving a significant risk of selection bias. Along with this no blinding took place in any of the studies leading to the potential of detection bias. Reporting bias is likely to be have been significant in two of the studies included in this review, Anderson (2002) and Coker et al. (1978). Anderson (2002) fails to report on all turf toe injuries that were managed conservatively. Coker et al. (1978) describes a case series of 18 cases but only provides limited outcomes for 8 of these cases. No set outcomes are provided across all the cases and no method is described as to how these cases were chosen or followed up.

Clanton and Ford (1994) noted in their study that at 5 years follow up $50 \%$ of those who suffered a turf toe injury remained symptomatic. This statistic highlights a limitation of the studies included in the review. The length of follow up ranged from 6 months to 10 years. In these studies, 
once participants had returned to pre-injury athletic activity they were often no longer followed up, therefore it is possible that symptoms may have recurred at a later date but not been reported. The studies included in this review considered time to return to preinjury athletic activity as the same as symptom resolution. However, George et al. (2014) noted that turf toe injury is more likely to occur in a match than practice and it can therefore be hypothesised that turf toe is more likely to become symptomatic during a game situation. It is likely that these studies failed to report participants long term outcomes of turf toe. The lack of long term follow up will also fail to demonstrate turf toe recurrence

Areas of proposed further study. The lack of high quality evidence within this review highlights the need for further research. There is currently no standardisation for the conservative management of turf toe with significant variability in current practice. Further research to define the treatment goals, optimal immobilisation technique and weightbearing status progression would be beneficial.

A randomised control trial comparing the outcomes of conservative vs operative management for grade 3 turf toe injury would also give further insight into which method if more effective for more severe injuries. This is a controversial area within this review identifying successful outcomes of those undergoing surgery for grade 3 turf toe. However, operative intervention may be unnecessary unless it gives a significant treatment benefit over conservative management given that there are risks of surgery.

\section{CONCLUSION}

This systematic review has shown that there is insufficient evidence to determine the circumstances in which operative intervention is superior to conservative management. However operative intervention for turf toe has shown to give a successful outcome to patients with a grade three turf toe injury and those who have suffered a grade two turf toe injury who have failed a trail of conservative management.

Disclosure. This work was presented at the $3^{\text {rd }}$ international Conference on Sports Medicine and Fitness, Barcelona, Spain and the abstract of this paper was presented at the international sports medicine and sports science conference. The poster abstract was published in poster abstracts in BJSM http://bjsm.bmj.com/content/51/Suppl_2/A7.3

Appendix 1. Reasons for article exclusion

\begin{tabular}{|c|c|c|c|}
\hline First author & Year & Title & Reason for exclusion \\
\hline Ainhoa & 2015 & $\begin{array}{l}\text { A variant neglected type IIIA dorsal dislocation of the first meta- } \\
\text { tarsophalangeal joint a case report }\end{array}$ & $\begin{array}{l}\text { No original data on turf toe } \\
\text { injury }\end{array}$ \\
\hline Ando & 2002 & $\begin{array}{l}\text { Irreducible dorsal subluxation of the first metatarsophalangeal } \\
\text { joint: A case report }\end{array}$ & $\begin{array}{l}\text { No original data on turf toe } \\
\text { injury }\end{array}$ \\
\hline Albers & 2003 & $\begin{array}{l}\text { Rehabilitation and taping techniques in the athlete: hallux and } \\
\text { first ray problems }\end{array}$ & $\begin{array}{l}\text { No original data on turf toe } \\
\text { injury }\end{array}$ \\
\hline Blakeslee & 1996 & Traumatic injuries of the first ray & Unable to Access Full Text \\
\hline Bouche & 2013 & First metatarsophalangeal joint sesamoidopathy & $\begin{array}{l}\text { No original data on turf toe } \\
\text { injury }\end{array}$ \\
\hline Bowers & 1976 & Turf Toe: A shoe surface related football injury & $\begin{array}{l}\text { No original data on the man- } \\
\text { agement of turf toe injury }\end{array}$ \\
\hline Brophy & 2009 & $\begin{array}{l}\text { Effect of turf toe on foot contact pressure in professional Ameri- } \\
\text { can Football players }\end{array}$ & $\begin{array}{l}\text { No original data on the man- } \\
\text { agement of turf toe injury }\end{array}$ \\
\hline Breen & 2010 & An Unusual Injury to the First Metatarsophalangeal Joint & $\begin{array}{l}\text { No original data on turf toe } \\
\text { injury }\end{array}$ \\
\hline
\end{tabular}


Appendix 1 (continued)

\begin{tabular}{|c|c|c|c|}
\hline First author & Year & Title & Reason for exclusion \\
\hline Caio Nery & 2017 & $\begin{array}{l}\text { MR Imaging of the Plantar PlateHow to classify plantar plate } \\
\text { injuries: parameters from history and physical examinationHow } \\
\text { to classify plantar plate injuries: parameters from history and } \\
\text { physical examinationHow to classify plantar plate injuries: pa- } \\
\text { rameters from history andHow to classify plantar plate injuries: } \\
\text { parameters from history and physical examination } \\
\text { How to classify plantar plate injuries: parameters from history } \\
\text { and physical examination } \\
\text { How to classify plantar plate injuries: parameters from history } \\
\text { and physical examination } \\
\text { How to classify plantar plate injuries: parameters from history } \\
\text { and physical examination } \\
\text { How to classify plantar plate injuries: parameters from history } \\
\text { and physical examination }\end{array}$ & $\begin{array}{l}\text { No original data on the man- } \\
\text { agement turf toe injury }\end{array}$ \\
\hline Carmont & 2004 & $\begin{array}{l}\text { Clutch foot stress fracture: another complication of } \\
\text { commuting?How to classify plantar plate injuries: parameters } \\
\text { from history and physical examination }\end{array}$ & $\begin{array}{l}\text { No original data on the man- } \\
\text { agement of turf toe injury }\end{array}$ \\
\hline Chou & 2000 & $\begin{array}{l}\text { Disorders of the first metatarsophalangeal joint: diagnosis of } \\
\text { great-toe pain }\end{array}$ & $\begin{array}{l}\text { No original data on turf toe } \\
\text { injury }\end{array}$ \\
\hline Churchill & 1998 & Managing injuries of the great toe & $\begin{array}{l}\text { No original data on turf toe } \\
\text { injury }\end{array}$ \\
\hline Clanton & 1994 & Turf toe injury & Unable to Access Full Text \\
\hline Coughlin & 2010 & $\begin{array}{l}\text { Turf toe: soft tissue and osteocartilaginous injury to } \\
\text { the first metatarsophalangeal joint }\end{array}$ & $\begin{array}{l}\text { No original data on turf toe } \\
\text { injury }\end{array}$ \\
\hline Coughlin & 2005 & Athletic injury to the first metatarsal phalangeal joint & Unable to Access Full Text \\
\hline de Palma & 1991 & „Slow“ fractures of the metatarsi & Article not in English \\
\hline Doty & 2013 & Turf toe repair: a technical note. & $\begin{array}{l}\text { Does not report on primary or } \\
\text { secondary outcome }\end{array}$ \\
\hline George & 2014 & $\begin{array}{l}\text { Incidence and risk factors for turf toe injuries in intercollegiate } \\
\text { football: data from the national collegiate athletic association } \\
\text { injury surveillance system }\end{array}$ & $\begin{array}{l}\text { Does not report on primary or } \\
\text { secondary outcome }\end{array}$ \\
\hline Glasco & 1998 & $\begin{array}{l}\text { Conservative evaluation and intervention of a sport-related in- } \\
\text { jury: Turf toe }\end{array}$ & $\begin{array}{l}\text { Original data only in paediatric } \\
\text { population }\end{array}$ \\
\hline Gorbachova & 2015 & Midfoot and Forefoot Injuries. & $\begin{array}{l}\text { Does not report on primary or } \\
\text { secondary outcome }\end{array}$ \\
\hline Graves & 1991 & $\begin{array}{l}\text { Posttraumatic proximal migration of the first metatarsophalan- } \\
\text { geal joint sesamoids: a report of four cases }\end{array}$ & Unable to Access Full Text \\
\hline Hall & 1992 & $\begin{array}{l}\text { A new type of dislocation of the first metatarsophalangeal joint: } \\
\text { a case report. }\end{array}$ & $\begin{array}{l}\text { No original data on turf toe } \\
\text { injury }\end{array}$ \\
\hline Hockenbury & 1999 & Forefoot problems in athletes & $\begin{array}{l}\text { No original data on turf toe } \\
\text { injury }\end{array}$ \\
\hline Hong & 2016 & Management of sports injuries of the foot and ankle & $\begin{array}{l}\text { No original data on turf toe } \\
\text { injury }\end{array}$ \\
\hline $\mathrm{Hsu}$ & 2016 & Foot and Ankle Injuries in American Football. & $\begin{array}{l}\text { No original data on turf toe } \\
\text { injury }\end{array}$ \\
\hline Hussain & 1999 & $\begin{array}{l}\text { Dislocation of the first metatarsophalangeal joint with fracture } \\
\text { of fibular sesamoid. A case report }\end{array}$ & $\begin{array}{l}\text { Does not report on primary or } \\
\text { secondary outcome }\end{array}$ \\
\hline Hunt & 2010 & Management of forefoot injuries in the athlete & $\begin{array}{l}\text { No original data on turf toe } \\
\text { injury }\end{array}$ \\
\hline Isefuku & 2004 & $\begin{array}{l}\text { Traumatic dislocation of the first metatarsophalangeal joint with } \\
\text { tibial sesamoid fracture: a case report. }\end{array}$ & $\begin{array}{l}\text { Does not report on primary or } \\
\text { secondary outcome }\end{array}$ \\
\hline
\end{tabular}


Appendix 1 (continued)

\begin{tabular}{|c|c|c|c|}
\hline First author & Year & Title & Reason for exclusion \\
\hline Jastifer & 2015 & $\begin{array}{l}\text { Exposure via sequential release of the metatarsophalangeal joint } \\
\text { for plantar plate repair through a dorsal approach without an } \\
\text { intraarticular osteotomy }\end{array}$ & $\begin{array}{l}\text { No original data on turf toe } \\
\text { injury }\end{array}$ \\
\hline Javed & 2016 & $\begin{array}{l}\text { Salvage of a complex first metatarso-phalangeal joint injury and } \\
\text { synchronous reconstruction of medial collateral ligament and } \\
\text { soft tissue with a distally based medial plantar artery flap. }\end{array}$ & $\begin{array}{l}\text { Does not report on primary or } \\
\text { secondary outcome }\end{array}$ \\
\hline Kadakia & 2011 & $\begin{array}{l}\text { Current concepts review: traumatic disorders of the first meta- } \\
\text { tarsophalangeal joint and sesamoid complex. }\end{array}$ & $\begin{array}{l}\text { No original data on turf toe } \\
\text { injury }\end{array}$ \\
\hline Kaplan & 2011 & $\begin{array}{l}\text { Incidence and variance of foot and ankle injuries in elite college } \\
\text { football players. }\end{array}$ & $\begin{array}{l}\text { Does not report on primary or } \\
\text { secondary outcome }\end{array}$ \\
\hline Killian & 1997 & Dorsal dislocation of the first metatarsophalangeal joint & $\begin{array}{l}\text { No original data on turf toe } \\
\text { injury }\end{array}$ \\
\hline Lee & 2011 & Hallux, sesamoid, and first metatarsal injuries & $\begin{array}{l}\text { No original data on turf toe } \\
\text { injury }\end{array}$ \\
\hline Lui & 2008 & $\begin{array}{l}\text { Stabilization of first metatarsophalangeal instability with plantar } \\
\text { plate tenodesis }\end{array}$ & $\begin{array}{l}\text { Does not report on primary or } \\
\text { secondary outcome }\end{array}$ \\
\hline Mares & 2016 & Management of Athletic Turf Toe Using Biologics & $\begin{array}{l}\text { Does not report on primary or } \\
\text { secondary outcome }\end{array}$ \\
\hline Maskill & 2006 & First ray injuries & $\begin{array}{l}\text { No original data on turf toe } \\
\text { injury }\end{array}$ \\
\hline Mason & 2015 & Turf Toe and Disorders of the Sesamoid Complex & $\begin{array}{l}\text { No original data on turf toe } \\
\text { injury }\end{array}$ \\
\hline Mata & 1998 & $\begin{array}{l}\text { Dorsal dislocation of the first metatarso-phalangeal joint - A } \\
\text { case report }\end{array}$ & $\begin{array}{l}\text { No original data on turf toe } \\
\text { injury }\end{array}$ \\
\hline McCormick & 2010 & Turf Toe Anatomy, Diagnosis, and Treatment & $\begin{array}{l}\text { No original data on turf toe } \\
\text { injury }\end{array}$ \\
\hline McCormick & 2010 & Rehabilitation following turf toe injury and plantar plate repair & $\begin{array}{l}\text { No original data on turf toe } \\
\text { injury }\end{array}$ \\
\hline McCormick & 2009 & $\begin{array}{l}\text { The great toe: failed turf toe, chronic turf toe, and complicated } \\
\text { sesamoid injuries }\end{array}$ & $\begin{array}{l}\text { No original data on turf toe } \\
\text { injury }\end{array}$ \\
\hline McCormick & 2013 & Surgical correction of the recalcitrant turf toe & Unable to Access Full Text \\
\hline Nabarro & 1995 & $\begin{array}{l}\text { Dorsal dislocation of the metatarsophalangeal joint of the } \\
\text { great toe: a case report }\end{array}$ & $\begin{array}{l}\text { Does not report on primary or } \\
\text { secondary outcome }\end{array}$ \\
\hline Nicholson & 2012 & Surgical management of turf toe injuries & $\begin{array}{l}\text { No original data on turf toe } \\
\text { injury }\end{array}$ \\
\hline Ozyurek & 2013 & $\begin{array}{l}\text { The eyes won't see what the mind doesn't think of"--Confucius } \\
\text { re: "how many joints does the } 5 \text { th toe have? A review of } 606 \\
\text { patients of } 655 \text { foot radiographs }\end{array}$ & $\begin{array}{l}\text { No original data on turf toe } \\
\text { injury }\end{array}$ \\
\hline Schein & 2015 & Turf toe and sesamoiditis: What the radiologist needs to know & $\begin{array}{l}\text { Does not report on primary or } \\
\text { secondary outcome }\end{array}$ \\
\hline Tosun & 2008 & $\begin{array}{l}\text { Traumatic dislocation of the first metatarsophalangeal joint with } \\
\text { entrapment of the flexor hallucis longus tendon. }\end{array}$ & $\begin{array}{l}\text { No original data on turf toe } \\
\text { injury }\end{array}$ \\
\hline Trikha & 2013 & Multiple floating metatarsals: a unique injury. & $\begin{array}{l}\text { No original data on turf toe } \\
\text { injury }\end{array}$ \\
\hline Vanore & 2005 & $\begin{array}{l}\text { Diagnosis and treatment of first metatarsophalangeal joint disor- } \\
\text { ders. Section 5: Traumatic disorders. }\end{array}$ & $\begin{array}{l}\text { No original data on turf toe } \\
\text { injury }\end{array}$ \\
\hline Watson & 2005 & $\begin{array}{l}\text { Periarticular injuries to the hallux metatarsophalangeal joint in } \\
\text { athletes. }\end{array}$ & $\begin{array}{l}\text { No original data on turf toe } \\
\text { injury }\end{array}$ \\
\hline Wilson & 2005 & $\begin{array}{l}\text { Radiologic case study. First metarsophalangeal plantar plate } \\
\text { injury (turf toe). }\end{array}$ & $\begin{array}{l}\text { Does not report on primary or } \\
\text { secondary outcome }\end{array}$ \\
\hline
\end{tabular}


Appendix 2. Data extraction template

\begin{tabular}{|l|}
\hline \multicolumn{1}{|c|}{ Publication Details } \\
\hline First author \\
\hline Year of publication \\
\hline \\
\hline Study design \\
\hline Sample size \\
\hline Participant age range \\
\hline Participant gender \\
\hline Grade of turf toe injury \\
\hline Time from injury to treatment initiation \\
\hline Type of treatment \\
\hline Time to return to athletic activity \\
\hline Time to resolution of symptom \\
\hline Length of follow up \\
\hline
\end{tabular}

Appendix 3. Results table summarising the included studies interventions and outcomes for the management of turf toe

\begin{tabular}{|c|c|c|c|c|c|c|c|c|c|c|}
\hline \multirow[b]{2}{*}{ Author } & \multirow{2}{*}{ 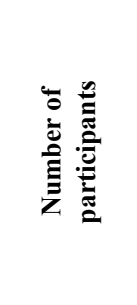 } & \multicolumn{2}{|c|}{$\begin{array}{c}\text { Intended } \\
\text { treatment } \\
\text { group }\end{array}$} & \multicolumn{2}{|c|}{ Actual treatment } & \multicolumn{2}{|c|}{$\begin{array}{l}\text { Average time to return to } \\
\text { preinjury activity }\end{array}$} & \multicolumn{2}{|c|}{$\begin{array}{l}\text { Average time to } \\
\text { resolution of symptoms }\end{array}$} & \multirow{2}{*}{$\begin{array}{l}\text { Length } \\
\text { of follow } \\
\text { up }\end{array}$} \\
\hline & & 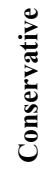 & 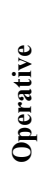 & 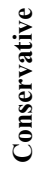 & : & 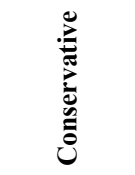 & రై & 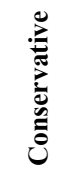 & రై & \\
\hline Anderson et al. & 19 & 10 & 9 & 10 & 9 & $\mathrm{~N} / \mathrm{A}$ & $\begin{array}{l}\text { No clear time } \\
\text { but } 7 \text { returned } \\
\text { to full athletic } \\
\text { activity }\end{array}$ & $\mathrm{N} / \mathrm{A}$ & $\begin{array}{l}2 \text { of the patients } \\
\text { had ongoing } \\
\text { symptoms at } 10 \\
\text { years }\end{array}$ & $\begin{array}{l}1-10 \\
\text { years }\end{array}$ \\
\hline Coker et al. & $\begin{array}{c}18 \text { (only } \\
8 \text { reported } \\
\text { on) }\end{array}$ & 5 & 3 & 4 & $\begin{array}{l}3 \text { (1X failed } \\
\text { conservative } \\
\text { management } \\
\text { and under- } \\
\text { went surgery) }\end{array}$ & $\begin{array}{l}3 \text { weeks } \\
\text { (outcome } \\
\text { reported } \\
\text { for } 1 \text { par- } \\
\text { ticipant) }\end{array}$ & $\begin{array}{c}12 \text { weeks } \\
\text { (outcome } \\
\text { reported on } \\
2 \text { participants) }\end{array}$ & N/A & $\begin{array}{l}\text { In two cases } \\
\text { they had ongo- } \\
\text { ing symptoms } \\
\text { despite } \\
\text { treatment }\end{array}$ & $\mathrm{N} / \mathrm{A}$ \\
\hline Drakos et al. & 3 & 1 & 2 & 1 & 2 & 24 weeks & 24 weeks & $\mathrm{N} / \mathrm{A}$ & N/A & $\begin{array}{c}6 \\
\text { Months }\end{array}$ \\
\hline Faltus et al. & 5 & 2 & 3 & 1 & 4 & 8 weeks & 15 Weeks & $\mathrm{N} / \mathrm{A}$ & $\mathrm{N} / \mathrm{A}$ & $\mathrm{N} / \mathrm{A}$ \\
\hline Lohrer et al. & 1 & 1 & 0 & 0 & 1 & $\mathrm{~N} / \mathrm{A}$ & 24 Weeks & N/A & N/A & $\begin{array}{c}6 \\
\text { Months }\end{array}$ \\
\hline Roche et al. & 1 & 0 & 1 & 0 & 1 & $\mathrm{~N} / \mathrm{A}$ & 22 Weeks & $\mathrm{N} / \mathrm{A}$ & N/A & $\begin{array}{c}2 \text { years } \\
6 \\
\text { months }\end{array}$ \\
\hline Sahin et al. & 1 & 1 & 0 & 0 & 1 & $\mathrm{~N} / \mathrm{A}$ & 12 Weeks & $\mathrm{N} / \mathrm{A}$ & N/A & $\begin{array}{c}10 \\
\text { months }\end{array}$ \\
\hline
\end{tabular}




\section{REFERENCES}

Anderson, R. B. (2002). Turf Toe injuries of the hallux metatarsophalangeal joint. Techniques in Foot \& Ankle Surgery, 1(2), 102-111.

Bouchette, E. (1985). Pittsburgh Post Gazette. 12/7/1985. Retrieved from http://www.post-gazette.com/sports/steelers/2007/10/14/From-the-PG-Archives-Toe-ends-Lambert-s-11-year-reign-as-Steeler-LB/stories/200710140234.

Bowers, K. D. Jr, \& Martin, R. B. (1976). Turf toe: a shoe-surface related football injury. Medicine \& Science in Sports \& Exercise, 8(2), 81-83.

Clanton, T. O., \& Ford, J. J. (1994). Turf toe injury. Clinics in Sports Medicine, 13, 731-741.

Clanton, T. O., Butler, J. E., \& Eggert, A. (1986). Injuries to the metatarsophalangeal joints in athletes. Foot Ankle, 7, 162-176.

Coker, R. P., Arnold, A. R, \& Weber, D. L. (1978). Traumatic lesions of the metatarsophalangeal joint of the great toe in athlete. Journal of the Arkansas Medical Society, 74(8), 309-317.

Douglas, D. P., Davidson, D. M., Robinson, J. E., \& Bedi, D. G. (1997). Rupture of the medial collateral ligament of the first metatarsophalangeal joint in a professional soccer player. Journal of Foot \& Ankle Surgery, 36, 388-390.

Drakos, M. C., Fiore, R., Murphy, C., \& DiGiovanni, C. W. (2015). Plantar-plate disruptions: "The Severe TurfToe Injury." Three cases in contact athletes. Journal of Athletic Training, 50(5), 553-560.

Faltus, J., Mullenix, K., Moorman, C. T., Beatty, K., \& Easley, M. E. (2014). Case series of first metatarsophalangeal joint injuries in Division 1 college athletes. American Journal of Sports Medicine, 6(6), 519-526.

Florio, M. (2015). NBC Sports. NBC 2015. Retrieved from http://profootballtalk.nbcsports.com/2010/02/15/ turf-toe-ends-patrick-passs-career

George, E. Harris, A. H. S., Dragoo, J. L., \& Hunt, K. J. (2014). Incidence and risk factors for turf toe injuries in intercollegiate football: Data from the national collegiate athletic association injury surveillance system. Foot \& Ankle International, 35(2), 108-115. https://doi. org/10.1177\%2F1071100713514038

Hägglund, M., Waldén, M., Magnusson, H., Kristenson, K., Bengtsson, H., \& Ekstrand, J. (2013). Injuries affect team performance negatively in professional football: An 11year follow-up of the UEFA Champions League injury study. British Journal of Sports Medicine, 47(12), 738742. http://dx.doi.org/10.1136/bjsports-2013-092215

Joseph, J. (1954). Range of movement of the great toe in men. Journal of Bone and Joint Surgery, 36(4), 50-57.
Lohrer, H. (2001). MP I joint giving way - a case study. Foot \& Ankle International, 22(2), 153-157. doi: 10.1177/107110070102200213

McCormick, J. J., \& Anderson, R. B. (2010). Rehabilitation following turf toe injury and plantar plate repair. Clinics in Sports Medicine, 29(2), 313-323. doi: 10.1016/j.csm.2009.12.010

McCormick, J. J., \& Anderson, R. B. (2009). The Great Toe: Failed turf toe, chronic turf toe, and complicated sesamoid injuries. Foot and Ankle Clinics, 14(2), 135150. doi: 10.1016/j.fcl.2009.01.001

McCormick, J. J., \& Anderson, R. B. (2010). Turf toe, anatomy, diagnosis and treatment. Sports Health, 2(6), 487-494. https://doi.org/10.1177\%2F1941738110386681

Mullis, D. L., \& Miller, W. E. (1980). A disabling sports injury of the great toe. Foot Ankle, 1, 22-25.

Nigg, B. M. (1986). Biomechanical aspects of running. Biomechanics of running shoes. Champaign IL, Human Kinetics.

Prieskorn, D., Graves, S. C., \& Smith, R. A. (1993). Morphometric analysis of the plantar plate apparatus of the first metatarsophalangeal joint. Morphometric analysis of the plantar plate apparatus of the first metatarsophalangeal joint. Foot Ankle, 14, 204-207. https://doi.org/10.1177\%2F107110079301400405

Roche, A. J., \& Calder, J. D. (2014). An atraumatic turf toe in an elite soccer player - a stress related phenomenon? Foot Ankle Surgery, 20(1).

Rodeo, S. A., O'Brien, S., Warren, R. F., Barnes, R., Wickiewicz, T. L., \& Dillingham, M. F. (1990). Turftoe: An analysis of metatarsophalangeal joint sprains in professional football players. American Journal of Sports Medicine,18(3), 280-285. https://doi.org/10.117 7\%2F036354659001800311

Sahin, N., Atici, T., Bilgen, S. M., \& Bilgen, O. F. (2004). Turf toe in a taekwandoo player: Case report. Journal of Sports Science and Medicine, 3(2), 96-100.

Stokes, I. A., Hutton, W. C., Stott, J. R., \& Lowe, L. W. (1979). Forces under the hallux valgus foot before and after surgery. Clinical Orthopaedics and Related Research, 142, 64-72.

VanPelt, M. D., Saxena, A., \& Allen, M. A. (2012). Turf toe injuries. International advances in foot and ankle surgery. Springer.

Watson, T. S., Anderson, R. B., \& Davis, W. H. (2000). Periarticular injuries to the hallux metatarsophalangeal joint in athletes. Foot \& Ankle Clinics, 5, 687-713. 